\title{
Acceptability and feasibility of strategies to promote healthy dietary choices in UK secondary school canteens: a qualitative study
}

Marie Murphy ${ }^{1,2^{*}} \mathbb{D}$, Daniel Mensah', Elena Mylona ${ }^{1}$ and Oyinlola Oyebode ${ }^{1}$

\begin{abstract}
Objective: To explore the acceptability and feasibility of choice architecture strategies for dietary change in UK secondary school canteens from the perspectives of pupils, school staff and catering providers through qualitative focus groups and interviews.

Results: Three focus groups with adolescents ( $n=15$; mean age 13.7 years; standard deviation 1.9) and eight interviews with school staff and caterers recruited from one school and catering provider in Coventry UK were undertaken. The most acceptable choice architecture strategies for intervening to drive healthy dietary choices are those that make use of proximity and positioning, on the basis that convenience was one of the main drivers for food/drink selections. Acknowledging adolescents' desire for autonomy and for food to be familiar and predictable was considered important in enhancing acceptability. Challenges to the feasibility of nudge strategies included concerns about behavioural issues, increased food waste, and a decline in uptake of canteen purchases. The design of food choice architecture interventions for secondary school settings should consider the specific characteristics of this age group and setting to ensure successful implementation.
\end{abstract}

Keywords: Choice architecture, Diet, Adolescents, Schools, Qualitative

\section{Introduction}

This research aimed to qualitatively explore the acceptability and feasibility of food choice architecture in a secondary school canteen, from the perspectives of pupils, staff and caterers. The objectives were to investigate:

1. Perspectives on choice architecture

2. Influences upon pupils' food choices in their school canteen

3. Opportunities and challenges facing schools in creating a healthy school canteen

\footnotetext{
${ }^{*}$ Correspondence: m.murphy.3@bham.ac.uk

${ }^{2}$ Present Address: Murray Learning Centre, Institute of Applied Health

Research, University of Birmingham, Birmingham B15 2TT, UK

Full list of author information is available at the end of the article
}

4. Attitudes towards specific nudge strategies and healthy eating messages

\section{Background}

Choice architecture (also known as 'nudge') is a behaviour change approach in which proximal physical microenvironments are altered to cue healthier behaviour [1]. Choice architecture may prove an effective means of changing dietary behaviours in adolescents in secondary schools given its effectiveness in other school and university settings [2]. However there is a lack of literature on attitudes towards nudge strategies despite the importance of attitudes in planning and evaluating interventions, including their acceptability, feasibility, economic viability, and theoretical underpinnings [3]. 


\section{Main text}

\section{Materials and methods}

This qualitative research consisted of focus groups (FGs) with pupils aged 11-18 years; and interviews with school staff, recruited from one secondary school in Coventry, UK. A school teacher invited potential participants and distributed information sheets (including aims of the study and reason for doing the research). The teacher was asked to invite adolescents representative of school demographics (age, sex, ethnicity, socioeconomic status) and staff participants in senior leadership, catering and pastoral roles. All those invited agreed to participate, however one adolescent did not have parental consent so was unable to take part.

Participants completed a questionnaire to collect demographic data (e.g. postcode, ethnicity, gender, age, job role). FGs and interviews were held on the school site, except for three telephone interviews (with staff). The facilitator (MM) used a semi-structured topic guide (developed by the authors; Additional file 1), and a second researcher (DM) took notes (during face-to-face data collection only). MM is a female Research Fellow with formal training and several years' experience in qualitative research methods. Card-sorting activities were used to understand attitudes towards specific nudge strategies (see Table 3) and healthy eating messages (Additional file 2). The research was guided by constructivist and pragmatic orientations.

\section{Data analysis}

FGs and interviews were audio recorded, transcribed then anonymised. All data were analysed using thematic framework analysis [4] in NVivo v12. Exploratory inductive double-coding of a sample of transcripts was undertaken (MM, OO and DM) followed by a meeting to agree a coding framework, to enhance the trustworthiness of the findings. All transcripts were included in the analysis, with data saturation achieved. One staff participant checked the findings to enhance the credibility of the findings.

\section{Results}

Fifteen adolescents participated in three FGs (mean age $=13.7$ years; standard deviation $=1.9 ; 53 \%$ female; $60 \%$ from Black and minority ethnic groups; $33 \%$ living in the top three deciles for deprivation), consisting of 4-6 participants and an average duration of $60 \mathrm{~min}$ (range: 56-64 min). Interviews were conducted with eight staff members, consisting of six school staff and two catering staff (75\% female; $37.5 \%$ aged $35-44$ years), with an average duration of $42 \mathrm{~min}$ (range: $29-55 \mathrm{~min}$ ). Table 1 displays participant characteristics.

A summary of the results of thematic analysis related to study objectives $1-3$ is provided, with example quotes provided in Table 2. Table 3 presents a summary of findings relating to objective 4 . The coding tree is provided in Additional file 3.

\section{Theme 1. Autonomy and informed decisions}

Staff felt a nudge approach would be appropriate in a secondary school setting because adolescents had little knowledge of nutrition/healthy food choices, so needed to be supported to make the right choices. There was a conflict in adolescents, between a desire to make informed decisions for themselves, and acknowledgement that they sometimes need to be "tricked" into making healthy choices. Both adults and adolescents referred to the idea of being "tricked" ambivalently. The line appeared to be drawn differently depending on the child's age, with a belief (from staff) in the need for increasing autonomy in decision-making for older adolescents.

\section{Theme 2. Value for money}

Adolescents and staff agreed that pricing was usually an important factor in children's lunch choices. Young people want to feel full after lunch, and will opt to get more food (quantity) for the same price when possible. Adolescents felt healthy food was more expensive, which discouraged healthy selections.

\section{Theme 3. Food and drink presentation}

Presentation was viewed as influential upon food choices for adolescents. Food needs to look appealing and ingredients need to be visible in dishes/on packaging to avoid any unwanted surprises in their meal.

\section{Theme 4. Adolescents' taste preferences and valuing of predictability}

For adolescents, taste was prioritised. 'Unhealthy food' e.g. pizza (in adolescents' descriptions) was viewed as more flavoursome, and there was high demand for these types of foods. Adolescents and staff agreed that healthy food would be more appealing if it tasted better. Caterers felt that in order to create appealing meals for adolescents, the healthiness of dishes had to be compromised to some extent.

Adolescents were viewed by adults as being reluctant to try new foods, which was echoed by adolescents reporting that they felt it was a high-risk option to try something new. Staff also felt that school was a setting in which adolescents could broaden their tastes but this contrasted with pupils' expectations that a canteen should provide familiar, preferred foods. 
Table 1 Adolescent and staff participant characteristics

\begin{tabular}{|c|c|c|c|c|c|}
\hline \multicolumn{6}{|c|}{ Adolescent participants } \\
\hline ID & Age & IMD decile ${ }^{a}$ & Gender & Ethnic group aggregated & Focus group \\
\hline A1 & 13 & 1 & Female & Not White British & Focus Group 1 \\
\hline A2 & 13 & 6 & Male & White British & Focus Group 1 \\
\hline A3 & 13 & 2 & Female & Not White British & Focus Group 1 \\
\hline A4 & 13 & 4 & Female & Not White British & Focus Group 1 \\
\hline A5 & 12 & 7 & Female & White British & Focus Group 1 \\
\hline A6 & 16 & 7 & Female & Not White British & Focus Group 2 \\
\hline A7 & 17 & 7 & Male & White British & Focus Group 2 \\
\hline A8 & 18 & 4 & Male & Not White British & Focus Group 2 \\
\hline A9 & 14 & 2 & Female & Not White British & Focus Group 2 \\
\hline A10 & 14 & 7 & Male & White British & Focus Group 2 \\
\hline A11 & 14 & 8 & Male & White British & Focus Group 2 \\
\hline $\mathrm{A} 12$ & 12 & 4 & Male & Not White British & Focus group 3 \\
\hline A13 & 12 & 5 & Male & White British & Focus group 3 \\
\hline A14 & 12 & 2 & Female & Not White British & Focus group 3 \\
\hline A15 & 12 & 1 & Female & Not White British & Focus group 3 \\
\hline \multicolumn{6}{|c|}{ Staff participants } \\
\hline ID & Age & & Gender & Role & \\
\hline C1 & $35-44$ & $\mathrm{n} / \mathrm{a}$ & Female & Catering staff & $\mathrm{n} / \mathrm{a}$ \\
\hline C2 & $35-44$ & $\mathrm{n} / \mathrm{a}$ & Female & Catering staff & $\mathrm{n} / \mathrm{a}$ \\
\hline S1 & $25-34$ & $\mathrm{n} / \mathrm{a}$ & Female & School staff & n/a \\
\hline S2 & $45-54$ & $\mathrm{n} / \mathrm{a}$ & Male & School staff & $\mathrm{n} / \mathrm{a}$ \\
\hline S3 & $25-34$ & $\mathrm{n} / \mathrm{a}$ & Female & School staff & $\mathrm{n} / \mathrm{a}$ \\
\hline S4 & $45-54$ & $\mathrm{n} / \mathrm{a}$ & Female & School staff & $\mathrm{n} / \mathrm{a}$ \\
\hline S5 & $55-64$ & $\mathrm{n} / \mathrm{a}$ & Male & School staff & $n / a$ \\
\hline S6 & $45-54$ & $\mathrm{n} / \mathrm{a}$ & Female & School staff & $\mathrm{n} / \mathrm{a}$ \\
\hline
\end{tabular}

${ }^{\mathrm{a}}$ IMD decile of home postcode. $1=$ most deprived decile

\section{Theme 5. Lunchtime is about more than just food}

Adolescents viewed lunchtime primarily as a time to spend with friends, with eating as a secondary activity. This view appeared to drive adolescents' beliefs and behaviours around purchasing habits, e.g. the desire for speed and convenience (the so-called "grab and go culture"); and the negative views of the canteen as a space to be in.

\section{Theme 6. Canteen-based barriers to a healthy school lunch}

Lunch service was considered too short in duration to enable healthy choices, and adolescents felt their choices were often rushed and poorly thought-out. The canteen was viewed as an unappealing space-hectic and crowded, with too many teachers present (observing; disciplining), and too little space for all pupils to have a sitdown meal. Another barrier was the competing demands upon caterers to balance the provision of healthy food with other factors e.g. minimising waste; profitability. Although the canteen was seen as part of the school 'community', with a moral purpose to provide healthy lunches to pupils, staff acknowledged that it was primarily a business, and needed to be viable. Healthy food items were viewed by some staff as less profitable, mainly because of low take-up and high levels of waste.

\section{Theme 7. Competing influences}

Staff felt that other, broader factors had a larger influence on adolescents' diets than the school setting e.g. home; society.

It was felt that one consequence of providing fewer 'unhealthy' options at school (e.g. cakes, cookies, pizza) was that customer numbers would decline as pupils sought these items from off-site outlets. For staff, the canteen was considered preferable to off-site outlets, since there was some degree of control over the nutritional content and purchasing of less healthy items on the school site.

The School Food Standards (SFS) were influential in restricting the sale of 'non-compliant' items e.g. sugary 


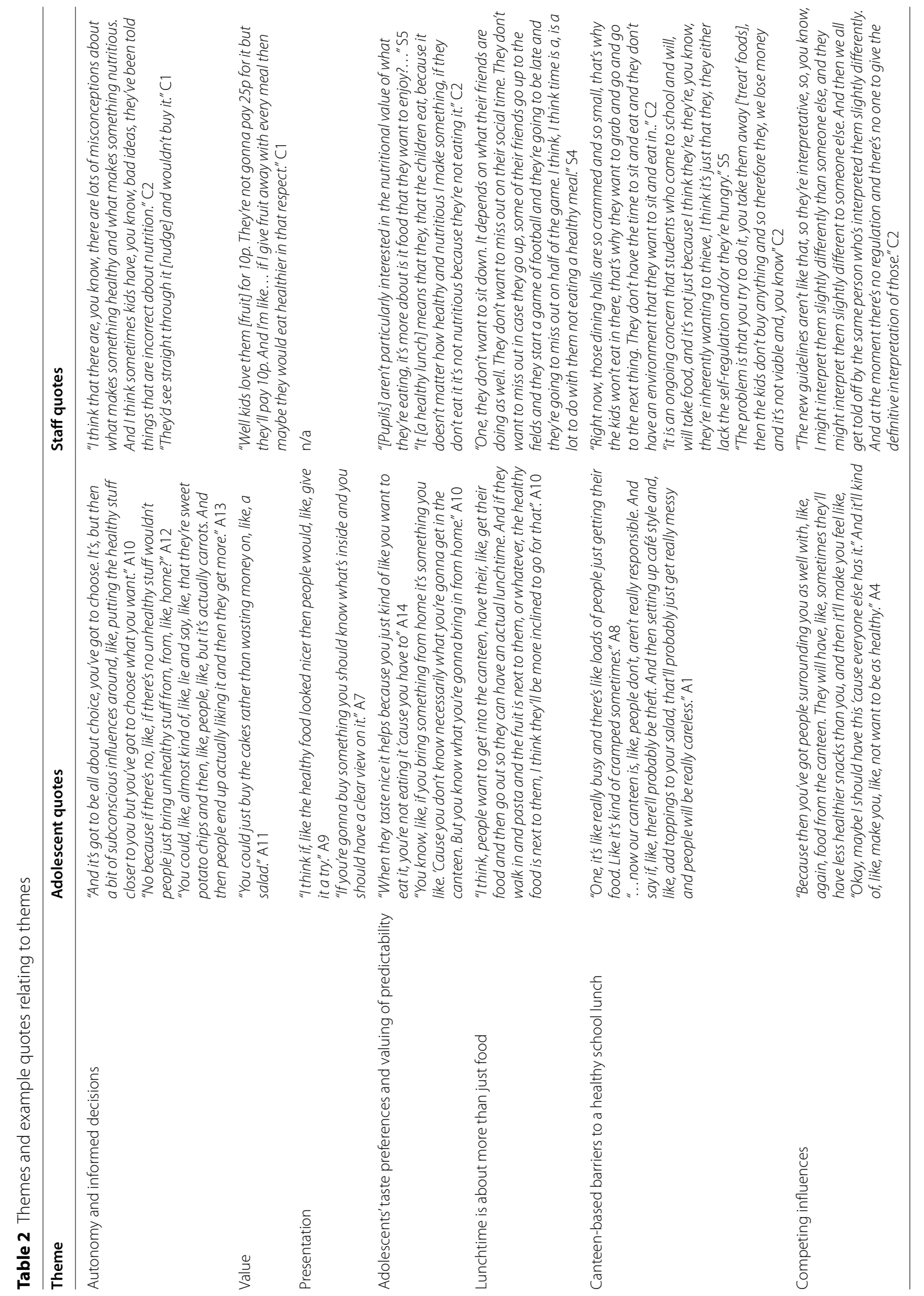


drinks. However, the SFS were viewed as open to interpretation, making implementation a challenge. The SFS did not appear as influential in the sixth form setting, since non-compliant items were available to buy in sixthform-only spaces. This was considered appropriate since older teens are more able to make responsible choices and need to be exposed to such food environments to prepare them for the outside world.

Caterers viewed themselves as the driving force behind making healthy choices available to schools. There appeared to be no external incentive for schools to provide a healthy lunch to adolescents, other than the school's own values/approach, which caterers found to vary widely across schools.

\section{Attitudes towards specific nudge strategies and healthy eating messages}

Views regarding specific nudge strategies are summarised in Table 3, categorised by type. The most feasible and appealing strategies were within the "position", "presentation" and "information" domains, with students additionally finding "availability" strategies appealing. The potential efficacy of some nudge strategies relying on presentation, information and positioning appeared to be reduced by the volume of pupils using the canteen in this school, reducing the visibility of, and obstructing access to, food counters and information. Many nudge strategies were considered unsuitable by both adolescents and staff because they provided additional opportunities for behavioural problems e.g. theft; mess.

The most appealing healthy eating messages were those that were short, factual and memorable. Messages focused on physical appearance or those that evoked feelings of guilt (e.g. "eat something good without feeling bad") were unpopular, viewed as unfair or stigmatising by adolescents. Messages that were positive or focused on feeling good (e.g. "choose well, feel great") were more appealing. Adolescents appeared to be influenced negatively by social pressure, and a reluctance to stand out/ deviate from the norm, which discouraged healthy eating. For adolescents and staff, the motivation to eat healthily was that a healthy meal provides fuel for learning. This tended to be focused on the need for volume, to 'fill' pupils up, but also extended to nutrient density and a balance of food groups.

\section{Critical discussion}

This study adds to our knowledge of the perceived drivers of adolescent food choices in the school canteen: convenience, presentation and value for money. In addition the findings highlight the perceived barriers to implementing nudge strategies imposed by the school canteen environment, e.g. short lunchbreaks; large volumes of customers; the need to achieve financial viability.

The current study identified position strategies (to make the healthy options the most convenient) as having high acceptability and feasibility. This supports other qualitative research in this age group [5]. Our study suggested that increased choice and availability of healthy items was highly acceptable to adolescents, supporting previous findings that the most effective interventions in increasing vegetable purchases/consumption were those where the variety was increased [6]. However, our findings provide some insight into the practicality of implementing such strategies. Caterers in the current study suggested that this approach would be a challenge to implement, due to the risk of increased waste and impact on financial viability. Two types of messaging appeared motivating for adolescents: messages that highlight how healthy choices support learning; and marketing strategies that focus on getting a large quantity of food for a low price.

The findings of this research have two potential uses in the design of future interventions: (1) identifying strategies that appear practically feasible to implement; and (2) building a theoretical underpinning for understanding why some strategies may be more effective than others in this population and setting, which will support the evaluation of any future intervention.

\section{Conclusions}

The study suggests that the general idea of 'nudging' for dietary change in a school canteen is acceptable to secondary school pupils, school staff and caterers, but that any choice architecture intervention implemented in a secondary school needs to be tailored to this age group and the setting to maximise successful implementation.

\section{Limitations}

These findings come from a limited number of participants all recruited from one school, so may not generalise to other schools. FGs incorporated pupils across mixed age groups, which may have impacted on the findings e.g. 13-15 year olds were generally less active in discussion when older pupils were present; and 11-13 year olds were generally the most enthused by the strategies proposed. Despite achieving a diverse sample, there may be some sampling bias due to pupils being selected by a teacher. We were only able to test a limited number of specific strategies, and have attempted to say something about intervention types more generally. Additional testing of a wider range of specific strategies within each of the most promising 'categories' of intervention types is needed. On this basis, the current study is a starting point for qualitatively exploring acceptability and feasibility. 


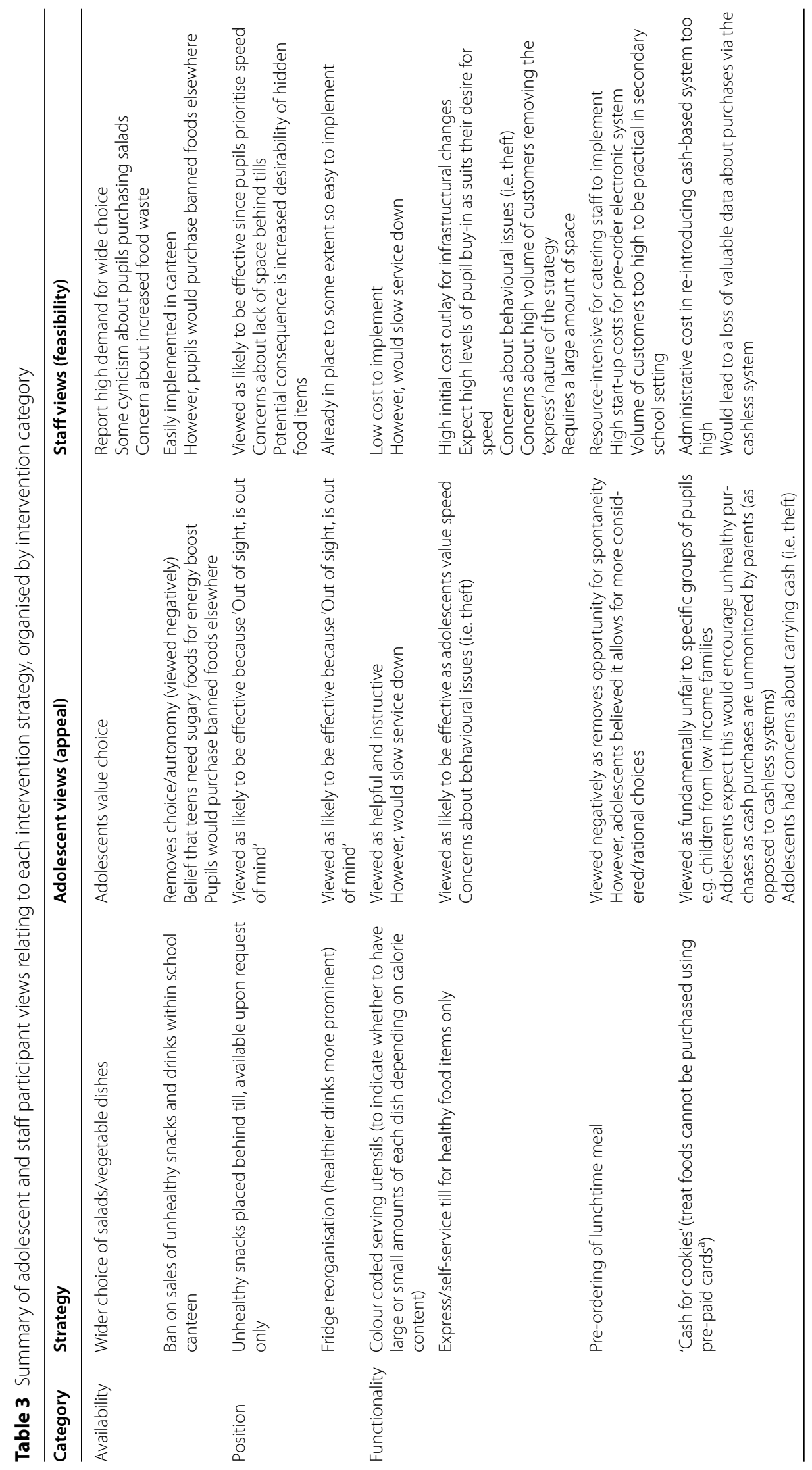




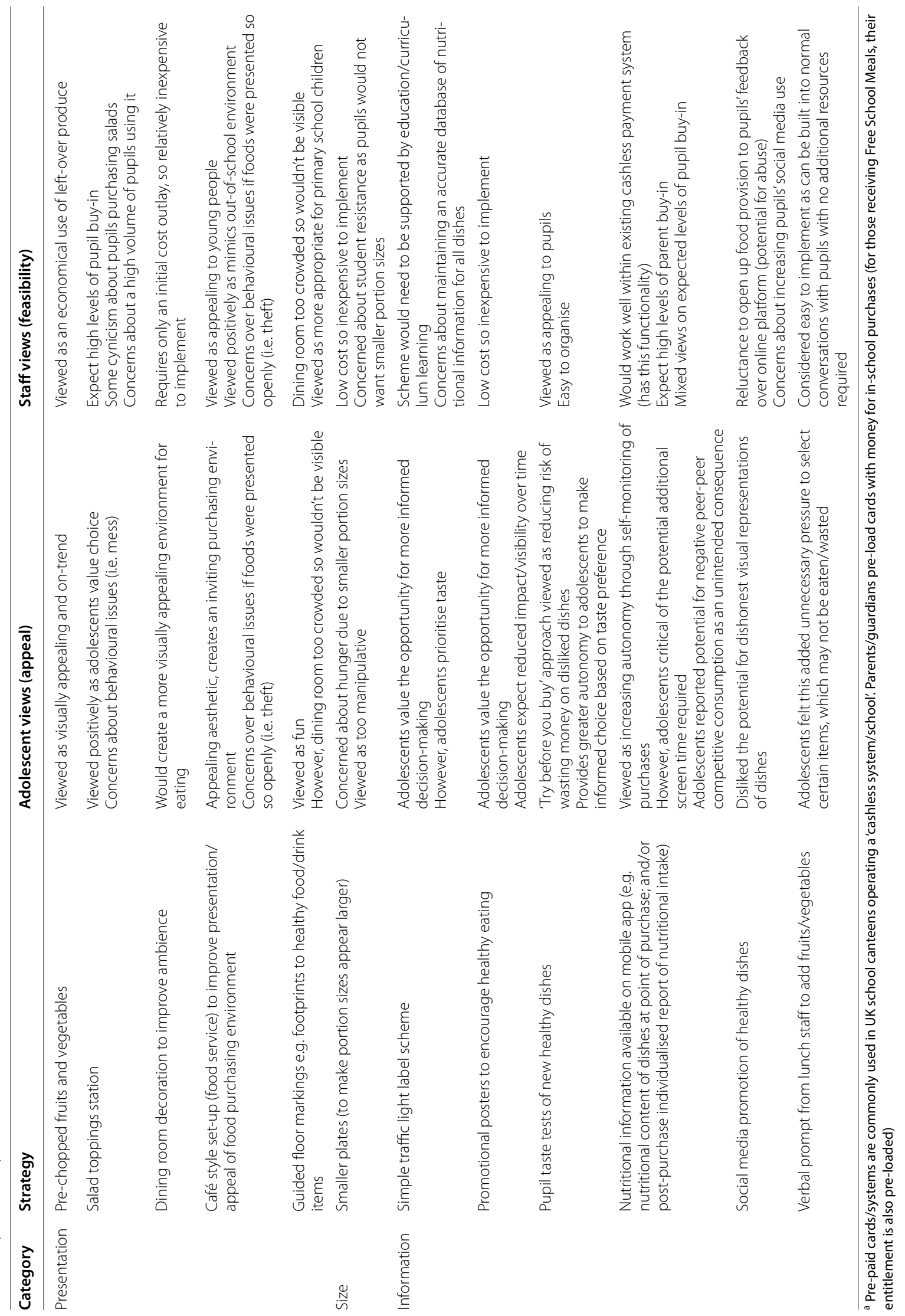




\section{Abbreviations}

FG: Focus group; IMD: Index of multiple deprivation; SFS: School Food Standards.

\section{Supplementary Information}

The online version contains supplementary material available at https://doi. org/10.1186/s13104-021-05778-3.

Additional file 1. Semi-structured topic guides for focus groups and interviews

Additional file 2. Summary of messages tested in focus groups with adolescents

Additional file 3. Coding tree for thematic analysis

\section{Acknowledgements}

The authors are grateful for the support of the school head teacher, student voice champion, and catering provider who supported the delivery of the study. Thank you to the pupils, teaching staff, catering staff and catering provider who participated in the focus groups and interviews. Thank you to Coventry City Council Public Health Team and South Warwickshire NHS Foundation Trust School Nursing Service for supporting the conception and design of the study.

\section{Authors' contributions}

MM and $\mathrm{OO}$ developed the study protocol. MM and DM carried out data collection. EM contributed to transcription of interviews. MM, OO and DM carried out analysis. All authors reviewed the manuscript. All authors read and approved the final manuscript.

\section{Funding}

This work was supported by Public Health England. The funders provided guidance on the original proposal. The funders were not involved in the undertaking of the study nor the writing of the manuscript. Oyinlola Oyebode is affiliated to the National Institute for Health Research (NIHR) Applied Research Collaboration (ARC) West Midlands. The views expressed are those of the author(s) and not necessarily those of the NIHR or the Department of Health and Social Care.

\section{Availability of data and materials}

The datasets generated and/or analysed during the current study are not publicly available as we do not have explicit participant consent to publish transcripts (which may contain identifiable data), but are available from the corresponding author in abridged and anonymised form on reasonable request.

\section{Declarations}

Ethics approval and consent to participate

Ethics approval was granted by the Biomedical and Scientific Research Ethics Committee at the University of Warwick (REGO-2018-2274). Written parental consent and verbal child assent was obtained for all child participants in the study. All adult participants provided written consent.

\section{Consent for publication}

Not applicable.

\section{Competing interests}

The authors declare that they have no competing interests.

\section{Author details}

${ }^{1}$ Warwick Medical School, University of Warwick, Coventry CV4 7AL, UK. ${ }^{2}$ Present Address: Murray Learning Centre, Institute of Applied Health Research, University of Birmingham, Birmingham B15 2TT, UK.

Received: 28 March 2021 Accepted: 7 September 2021

Published online: 20 September 2021

\section{References}

1. Hollands GJ, Bignardi G, Johnston M, Kelly MP, Ogilvie D, Petticrew M, et al. The TIPPME intervention typology for changing environments to change behaviour. Nat Hum Behav. 2017;1:0140.

2. Kongsbak I, Skov LR, Nielsen BK, Ahlmann FK, Schaldemose H, Atkinson $L$, et al. Increasing fruit and vegetable intake among male university students in an ad libitum buffet setting: a choice architectural nudge intervention. Food Qual Prefer. 2016;49:183-8.

3. Craig P, Dieppe P, Macintyre S, Michie S, Nazareth I, Petticrew M. Developing and evaluating complex interventions: the new Medical Research Council guidance. BMJ. 2008;337:a1655.

4. Gale NK, Heath G, Cameron E, Rashid S, Redwood S. Using the framework method for the analysis of qualitative data in multi-disciplinary health research. BMC Med Res Methodol. 2013;13(1):117.

5. Ensaff H, Coan S, Sahota P, Braybrook D, Akter H, McLeod H. Adolescents' food choice and the place of plant-based foods. Nutrients. 2015;7(6):4619-37.

6. Nornberg TR, Houlby L, Skov LR, Perez-Cueto FJ. Choice architecture interventions for increased vegetable intake and behaviour change in a school setting: a systematic review. Perspect Public Health. 2016;136(3):132-42.

\section{Publisher's Note}

Springer Nature remains neutral with regard to jurisdictional claims in published maps and institutional affiliations.
Ready to submit your research? Choose BMC and benefit from:

- fast, convenient online submission

- thorough peer review by experienced researchers in your field

- rapid publication on acceptance

- support for research data, including large and complex data types

- gold Open Access which fosters wider collaboration and increased citations

- maximum visibility for your research: over 100M website views per year

At BMC, research is always in progress.

Learn more biomedcentral.com/submissions 